\title{
FisLab.net, un laboratori virtual de física
}

\author{
Tavi Casellas i Gispert \\ IES-SEP Montilivi de Girona \\ ocasella@xtec.cat
}

Les noves tecnologies ofereixen moltes possibilitats per millorar l'ensenyament i l'aprenentatge de la física. Els applets, simulacions interactives dintre d'una pàgina web (www.fislab.net), en són una petita mostra i poden ser una gran ajuda pel professorat $i$, lògicament, per l'alumnat.

Fa una colla d'anys em rondava pel cap la idea de crear simulacions informàtiques de processos físics que poden ser difícils d'experimentar o visualitzar pels alumnes. Podem pensar, per exemple, en el dibuix de les línies equipotencials d'una distribució de càrregues puntuals o en les interferències ondulatòries.

Durant molt de temps les prestacions del programari i del maquinari no permetien realitzar còmodament aquest projecte. Però amb l'aparició al mercat de llenguatges de programació que facilitaven el treball en entorns gràfics i, sobretot, la millora de les prestacions del maquinari, conjuntament amb l'obtenció d'una llicència d'estudis del Departament d'Ensenyament, em van permetre portar a terme FisLab.net (fig. 1), el laboratori virtual de Física.

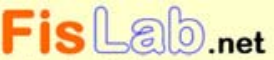

Figura 1. Capçalera de FisLab.net on podem veure els diferent recursos que ofereix el laboratori virtual de Física.

Durant el curs 2004-2005 vaig poder dissenyar i desenvolupar un conjunt d'applets adreçats bàsicament als professors i alumnes de Física de batxillerat i englobar-los en una pàgina web

\section{www.fislab.net}

conjuntament amb altres recursos i enllaços interessants dins del camp de la Física o de les Ciències en general.

\section{Corren nous temps...}

És cert. En els darrers anys la tecnologia ha avançat de forma espectacular i això ens afecta -positivament, és clar- al professorat de física perquè ens ha permès incorporar nous recursos pedagògics a l'ensenyament clàssic de la ciència: pissarra, guix i experiments al laboratori.

Ja fa una colla d'anys l'aparició del vídeo, també les transparències, va revolucionar la nostra tasca docent. Darrerament hem pogut comprovar la utilitat de les noves eines tecnològiques: internet, DVD, sensors, webquests, projector de vídeo, applets, animacions, aules virtuals...

És veritat que aquests recursos són de gran utilitat, però també cal que els sapiguem fer servir en la mesura correcta. I sobretot seleccionar per a cada unitat didàctica aquells que més facilitin a l'alumne la comprensió dels conceptes i la resolució dels procediments de la nostra matèria.

Per a nosaltres comença, o ha començat, una etapa on hem de realitzar com a mínim tres tasques importants:

- Recerca dels recursos i coneixement del seu funcionament.

Cada vegada és més difícil en el nostre món global estar al dia de l'aparició dels nous recursos. Per tant, haurem de confiar cada vegada més en la formació i en comunicacions específiques que ens ajudin a descobrir fàcilment aquests recursos.

- Selecció dels recursos més indicats per a cada objectiu.

De vegades trobem recursos que, malgrat ser atractius, no aporten cap avantatge per a l'ensenyament de la Física. En canvi, n'hi ha d'al- 
tres que segurament estan pensats per a nivells superiors al batxillerat. Entre uns i altres nosaltres hem de seleccionar els més adequats pel nivell educatiu del nostre alumnat i també per la nostra forma d'impartir la docència.

\section{- Organització d'aquests recursos.}

Cal sobretot que el professorat els tingui disponibles i localitzats just en el moment que els necessiti i també que els pugui oferir als alumnes com a part essencial del seu aprenentatge. En aquest sentit ens poden ajudar també les noves tecnologies: aules virtuals, pàgina web de la matèria...

\section{Noves eines... noves dinàmiques}

Tot aquest ventall de noves possibilitats fa que la dinàmica, l'organització, el treball... a l'aula de física vagi canviant de mica en mica.

L'ensenyament de la física està entrant (o potser ja hi som completament dins) en una fase de "revolució", sense que això ens hagi de comportar més angoixes de les habituals. D'aquí a uns anys ha de ser -serà- completament normal l'explicació del professor a l'aula amb el suport d'un projector de vídeo, l'experimentació al laboratori amb l'ajut de sensors electrònics, la realització d'exercicis individuals a l'aula d'informàtica amb l'ajut de simulacions interactives..

També l'alumne haurà de canviar la seva forma d'aprendre: aquests nous recursos afavoreixen l'autonomia, l'autoaprenentatge, la globalització de conceptes, l'aprenentatge a ritmes diferents, la utilització de recursos diversos segons la necessitat personal...

\section{I... FisLab.net què hi diu?}

El laboratori virtual de física (www.fislab.net) conté alguns d'aquests nous recursos (applets, apunts, exercicis i enllaços) adreçats tant al professorat com a l'alumnat de física.

Els applets són, però, el tema "estrella" de la pàgina. Es tracta de simulacions interactives, realitzades en llenguatge Java, sobre fenòmens concrets de la física que corren dintre d'una pàgina web i que permeten l'observació qualitativa, però també l'obtenció de resultats numèrics.

\section{Els professors podrem utilitzar els applets...}

- Per millorar l'explicació tradicional a l'aula (ara amb pissarra, guix... i l'applet projectat a la pan- talla). A tall d'exemple, l'explicació del moviment parabòlic amb l'ajut de l'applet permet a l'alumne visualitzar amb facilitat algunes propietats importants com ara que la component horitzontal de la velocitat es manté constant al llarg de la trajectòria, que el moviment és una superposició d'un MRU horitzontal i un MRUA vertical, que el vector acceleració és sempre constant, vertical i cap avall... També permetrà l'anàlisi amb una agilitat sorprenent de diverses situacions: llançament horitzontal, abast màxim, superació o no d'obstacles, components de les velocitats en el punt d'alçada màxima...

- Per fer treballar els alumnes, individualment o per parelles, a l'aula d'informàtica. La interacció alumne-applet afavorirà el seu aprenentatge. Podem deixar-los una estona per "jugar" educativament amb l'applet però haurem d'acabar amb una proposta seriosa de resolució de qüestions qualitatives (com varia la component horitzontal de la velocitat?) o de problemes numèrics (quina és l'alçada màxima?) que l'alumne ha de resoldre personalment. L'applet el pot ajudar a comprovar la correcció de la seva resposta o a trobar el camí per a la resolució. A tall de proposta, la pàgina web inclou per a cada applet una proposta de 5 qüestions i 5 problemes, més o menys ordenats per dificultat, amb una petita ajuda per a resolució, i la corresponent solució.

- Per preparar exercicis, problemes o exàmens. La interactivitat dels applets i les dades numèriques, tant d'entrada com de sortida, que proporcionen permeten simular una situació determinada per poder redactar després amb facilitat un problema o exercici per als alumnes.

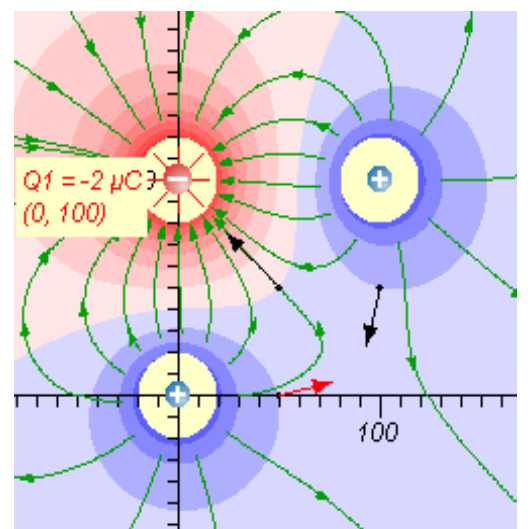

Figura 2. Detall de l'applet Electrostàtica de FisLab.net. Podem observar amb facilitat les línies de camp, les equipotencials, els vectors camp i les seves relacions. 
Però FisLab.net també ha de ser útil per als alumnes...

- Per millorar la seva capacitat d'autoaprenentatge i potenciar l'autonomia personal. Cada alumne pot utilitzar els applets i les propostes de qüestions i problemes per aprendre, millorar, aprofundir, repassar, resoldre... els conceptes i procediments que ell mateix decideixi en funció del seu nivell en la matèria.

- Per millorar l'assoliment de conceptes teòrics, perquè en poder visualitzar (amb vectors, trajectòries, línies...) situacions molt diverses (velocitat positiva, negativa, alçada inicial nul.la...) li permet comprovar virtualment allò que de forma abstracta possiblement li seria més difícil.

- Per resoldre problemes. No solament els applets permeten que l'alumne "s'inventi" enunciats de problemes (aspecte educatiu en ell mateix) sinó que li proporciona la solució numèrica a tot allò que ell mateix s'hagi plantejat. Els applets són, també en aquest sentit, una bona eina d'autoaprenentatge.

- Per a la preparació de proves i exàmens, tant des del punt de vista conceptual com procedimental.

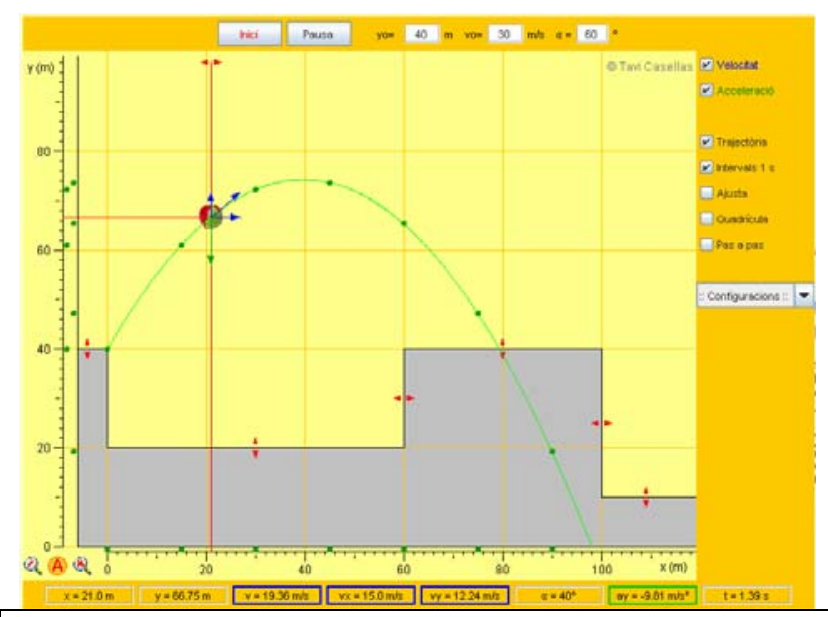

Figura 3. Applet de Moviment parabòlic de FisLab.net on podem veure les barres d'entrada (superior), de control (dreta) i de sortida (inferior). Els elements vermells són sensibles al ratolí: fletxes de desplaçament i lupes (+, A i -).

\section{Com funcionen els applets de FisLab.net?}

L'estructura (fig. 3) i funcionament dels diferents applets és sempre molt similar. Cal destacar alguns aspectes generals, tot i que segurament els acaba- rem fent funcionar intuïtivament (especialment els alumnes):

Barra d'entrada. De color taronja, està situada a la part superior de l'applet i conté els botons per fer funcionar els applets dinàmics (Inici, Pausa...) així com les caixes per escriure els paràmetres d'entrada (posició, velocitat, acceleració... inicials).

Barra de control. De color taronja i situada a la dreta de l'applet. Permet controlar la presentació d'alguns elements (vectors, marcadors de posició, línies...), ajustar el moviment del ratolí a determinades posicions, escollir configuracions preestablertes, triar el tipus de valors de sortida...

Barra de sortida. A la part inferior de l'applet i de color taronja. En aquesta barra podem llegir en tot moment els valors numèrics de les magnituds més interessants relacionades amb l'applet (posició, velocitat, acceleració, temps, força, camp elèctric, potencial...).

Elements vermells. En tots els applets s'ha tingut cura de reservar el color vermell per a tots aquells elements que són actius al ratolí i per tant es poden modificar clicant o arrossegant. Per exemple: les puntes vermelles dels vectors velocitat 0 acceleració, doble fletxa vermella per variar la posició o alçada, la lupa vermella per utilitzar el zoom de pantalla...

\section{Algunes ajudes...}

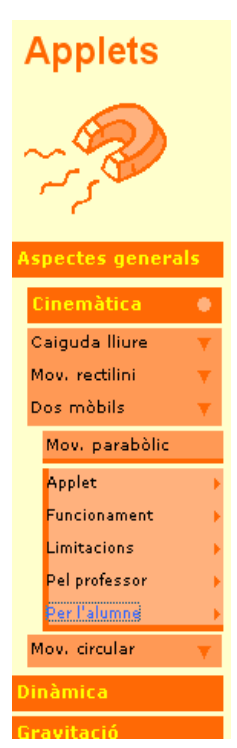

A la mateixa pàgina i dins de l'apartat Applets disposem d'un menú desplegable (a l'esquerra) que conté alguns elements interessants i que cal tenir en compte.

Per a cada applet disposem d'una explicació (textual i gràfica) sobre el seu funcionament, d'un comentari sobre les limitacions que té cada simulació (valors màxims i mínims, píxels de pantalla, angles possibles...), d'un conjunt de recomanacions per al professor (quins conceptes i procediments pot explicar amb l'ajut de l'applet, quina seqüència de simulacions convé utilitzar, quins tipus de problemes es poden resoldre...) i, finalment, un apartat per a l'alumne que conté l'enunciat, una ajuda i la solució a 5 qüestions conceptuals i 5 problemes numèrics sobre la temàtica de l'applet.

És important comentar aquest darrer apartat amb l'alumnat perquè és una senzilla proposta 
d'autoaprentatge que alguns, o molts, dels nostres alumnes de Física poden aprofitar.

\section{Quins i quants?}

En aquests moments hi ha un conjunt de 12 applets sobre cinc àmbits de la Física de batxillerat. En el procés de selecció de quines simulacions es portaven a terme hi han intervingut aspectes molt diversos, com ara:

- Percepció de la utilitat d'un simulador en l'explicació clàssica d'un tema (caiguda lliure, moviment parabòlic).

- Trobada a la xarxa d'algun applet interessant que es podia millorar (moviment rectilini).

- Dificultat gràfica en l'explicació clàssica del tema (electrostàtica, interferències).

- Grau de dificultat en el disseny i en la programació informàtica.

Els temes i applets són:

- Cinemàtica: Moviment rectilini, Caiguda lliure, Dos mòbils, Moviment parabòlic i Moviment circular

- Dinàmica: Pla inclinat, Dos objectes i Xocs

- Electrostàtica: Electrostàtica

- Gravitació: Gravitació

- Ones: Ones i Interferències

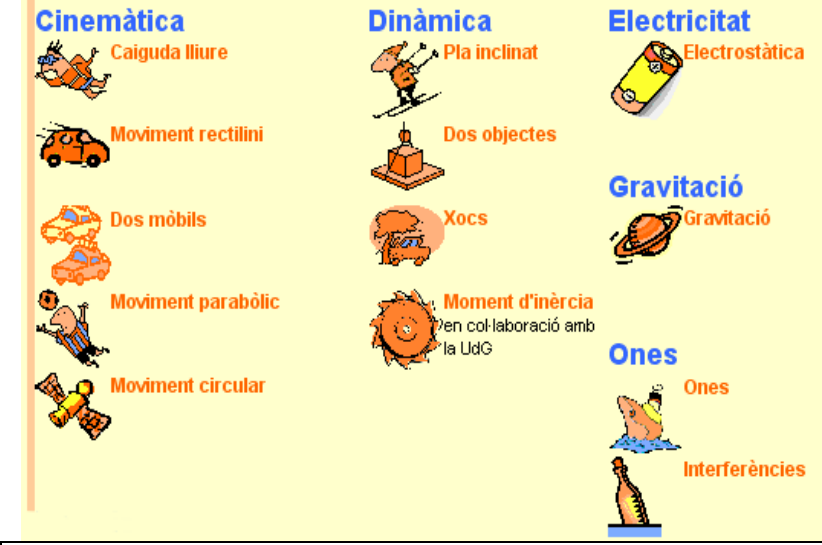

Figura 4. Pàgina general dels applets de FisLab.net. Els trobem agrupats per temes i podem "engegar-los" fàcilment.

\section{I ara...?}

Queda, lògicament, la porta oberta a l'ampliació del laboratori virtual a nous applets per anar completant el currículum de la física de batxillerat, tot i que la tasca de creació comporta una dedicació temporal difícilment compatible amb la docència.

En aquest sentit s'admeten (sense compromís) noves propostes, suggeriments, crítiques i aportacions per millorar l'efectivitat educativa de FisLab.net. 